\title{
Evaluation of Radar Backscattering Models IEM, OH, and Dubois using L and C-Bands SAR Data over different vegetation canopy covers and soil depths
}

\author{
S.Khabazan $^{\text {a }}$, M.Motagh ${ }^{\text {a }}$, M.Hosseini ${ }^{\text {b }}$ \\ ${ }^{\text {a }}$ University of Tehran, Remote Sensing Division, Surveying and Geomatics Engineering Department, College of \\ Engineering, North Kargar, Tehran 1439957131 Iran (s.khabazan, m.motagh)@ut.ac.ir \\ ${ }^{\mathrm{b}}$ Université de Sherbrooke, Centre d'applications et de recherches en télédétection (CARTEL), QC, Canada
}

KEY WORDS: Soil moisture, Dubois model, Integral equation model (IEM), Oh model, Soil depth, NDVI, AIRSAR

\begin{abstract}
:
Several algorithms have been proposed in the literature to invert radar measurements to estimate surface soil moisture. The objective of this paper is to compare the performance of the most common surface back scattering models including the theoretical integral equation model (IEM) of Fung et al(1992)., and the semi-empirical models of Oh et al (1992, 1994, 2002 and2004). and Dubois et al (1995).. This analysis uses four AIRSAR data in L and C band together with in situ measurements (soil moisture and surface roughness) over bare soil and vegetation covers area and three different soil depths. The results show that Dubois model tend to over-estimate the radar response in both bands while IEM model and Oh model frequently over-estimate the radar response in L band but under-estimate them in $\mathrm{C}$ band. By evaluating of all models in different soil depths, the best results were obtained in $0-3 \mathrm{~cm}$ depths. For vegetation area poor correlation between models backscatter simulation and radar response was observed.
\end{abstract}

\section{Introduction}

Soil moisture is an important parameter in many applications such as hydrology, agriculture, risk prediction and climate studies (Alvarez-Mozos et al., 2005; Beljaars et al., 1996; Georgakakos et al., 1996). Due to the high dependence of the microwave dielectric constant on soil water content, there is a high correlation between the radar backscattering coefficient and soil moisture (Panciera et al., 2009; Srivastava et al., 2009). Accordingly, much research has been done in the past to estimate soil moisture using Synthetic Aperture Radar (SAR) images ( Ulaby et al., 1996; Zribi et al., 2008; Song et al., 2009) and different empirical, semi-empirical, and theoretical soil moisture estimation models have been developed (Atemma and Ulaby, 1978; Oh et al., 1992; Fung et al.,). Among the numerous semi-empirical models reported in the literature the most popular ones are those developed by Oh (Oh et al. 1992, 1994, 2002, Oh 2004) and Dubois et al. (1995). The Oh model uses the ratios of the measured backscatter coefficients $p=\sigma_{H H}^{0} / \sigma_{V V}^{0}$ and $p=\sigma_{H V}^{0} / \sigma_{V V}^{0}$, and cross-polarized backscatter coefficient $\sigma_{H V}^{0}$ to estimate volumetric soil moisture and surface roughness, while the Dubois model links the backscatter coefficients in $\mathrm{HH}$ and $\mathrm{VV}$ polarizations to the soil's dielectric constant and surface roughness. The physical approach uses theoretical models that predict the radar backscatter coefficient from radar parameters and soil characteristics. The physical models provide site-independent relationships, but have limited roughness domains. The integral equation model (IEM) (Fung et al. 1992) is the most commonly used physical model in inversion procedures for the retrieval of soil moisture and/or roughness parameters.

Extensive studies have evaluated various models, but conflicting results have been obtained. Some studies have shown good agreement between measured backscatter coefficients (Rakotoarivony et al. 1996, Zribi et al. 1997, Satalino et al. 2002) and those predicted by the models, while others have found great discrepancies between them (Shi et al. 1997, Bindlish and Barros 2000, Baghdadi et al. 2004). The objective of this research is to evaluate and compare the accuracies of the three most popular models used in inversion procedures (the Oh, Dubois and IEM models) using L and C bands over different soil depths and vegetation canopy cover.

\section{Database}

\subsection{Study area}

The study area is located in southwest Oklahoma in the Southern Great Plains region of the United States and covers an area of 611 sq. km. The Little Washita Experimental Watershed (LWREW) is the focus of the Southern part of Oklahoma (OS) which is dominated by grassland. The location of these regions is shown in Figure 1, which is a Landsat-5 TM images collected on 10 July 2003. Figure 1 shows a combination of bands 4, 3, and 2 as the red, green, and blue channels. Red, white, and blue pixels indicate vegetation, bare soil, and dormant or senescent vegetation, respectively. The specifications of the study area are shown in Table 1.

\subsection{Field data}

The data used in this study is the Soil Moisture Experiments (SMEX03) data set that was gathered on 10 June 2003. 
International Archives of the Photogrammetry, Remote Sensing and Spatial Information Sciences, Volume XL-1/W3, 2013 SMPR 2013, 5 - 8 October 2013, Tehran, Iran

\begin{tabular}{|c|c|c|c|c|c|c|}
\hline Study Site & Location & & Vegetation & topography & $\begin{array}{c}\text { Range of mv } \\
(\%)\end{array}$ & $\begin{array}{l}\text { Range of rms } \\
\text { (cm) }\end{array}$ \\
\hline \multirow{4}{*}{ Little Washita Watershed } & Corner NW & $35.01 \mathrm{~N}$ & \multirow{4}{*}{$\begin{array}{c}\text { rangeland and } \\
\text { pasture }(63 \%) \text { with } \\
\text { significant areas of } \\
\text { winter wheat }\end{array}$} & \multirow{4}{*}{$\begin{array}{l}\text { moderately } \\
\text { rolling }\end{array}$} & \multirow{4}{*}{$0.7-28.8$} & \multirow{4}{*}{$0.6592-2.0927$} \\
\hline & \multirow{3}{*}{ Corner SE } & $98.03 \mathrm{~W}$ & & & & \\
\hline & & $34.75 \mathrm{~N}$ & & & & \\
\hline & & $97.89 \mathrm{~W}$ & & & & \\
\hline
\end{tabular}

Table 1. Study area

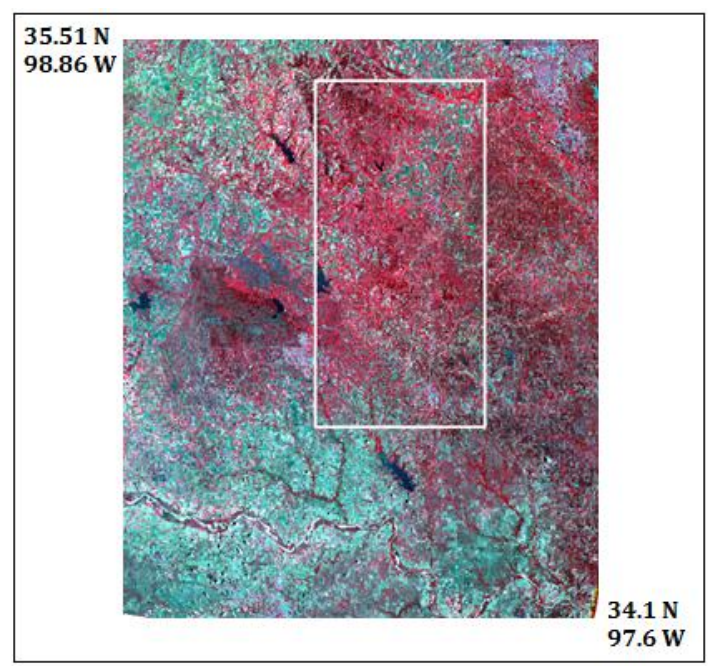

Figure 1. Landsat-5 TM image showing the general locations of the study region.

Sampling was performed on sites approximately one-quarter section, $0.8 \mathrm{~km}$ by $0.8 \mathrm{~km}$, in size. Soil samples were collected and soil temperature, surface temperature, soil dielectric constants were measured. In each site, soil moisture at $0-6 \mathrm{~cm}$ soil depth was measured using theta probe (TP). Also, at the time of sampling, a sampling tool was used to extract VSM and bulk density (BD) of $0-3 \mathrm{~cm}$ and $3-6 \mathrm{~cm}$ soil depth layers. The little Washita watershed dataset contains 13 sites and 54 points in all these sites. From total 54 sample points, 16 points have NDVI values in the range of $0-0.2$ and 16 points have NDVI values in the range of $0.2-0.4$ and 20 points have NDVI values in the range of 0.4-0.6. A $1 \mathrm{~m}$ roughness tablet was used to measure surface roughness. First the grid board was placed on soil vertically and a photo was taken. Then using these photos surface heights were digitized

at about $0.5 \mathrm{~cm}$ intervals, and then the root mean squared height ( $h_{r m s}$ ) parameter was calculated: (http://nsidc.org/data/docs/daac/nsidc0345_smex03_ancillary_s urface_roughness/index.html)

$h_{r m s}=\left(\frac{1}{n} \sum_{i=1}^{n}\left(\mathrm{Z}_{i}-\bar{Z}\right)^{2}\right)^{1 / 2}$

Where $\mathrm{n}$ is the number of measurements of the height, $\mathrm{Z}_{i}$ is a single measurement, and $\bar{Z}$ is the mean of the measurements. To determine the correlation length and the correlation length function, the surface autocorrelation curve was computed. Once the autocorrelation curve has been computed, the correlation length can be determined. The correlation length is defined as the distance $(d)$ at which the autocorrelation is less than $e^{-1}$. The correlation length can then be used to fit the theoretical correlation function to the measured autocorrelation curve by optimizing the power coefficient $(n)$.

\subsection{Satellite data}

In this study four Airborne Synthetic Aperture Radar (AIRSAR) images were used. AIRSAR is side-looking airborne radar and its data is in Stokes matrix format with a pixel size of $6.66 \mathrm{~m}$ in range and $9.26 \mathrm{~m}$ in azimuth. The incidence angle varies between $20^{\circ}$ and $70^{\circ}$. The images were taken in polarimetric mode (POLSAR) and are used to produce SMEX03. In this mode data is collected in three frequencies $\mathrm{C}$, $\mathrm{L}$, and $\mathrm{P}$ and in four different polarizations $\mathrm{HH}, \mathrm{VV}, \mathrm{HV}$, and $\mathrm{TP}$ (total power). The data used in this research were acquired in frequency $\mathrm{L}$ and $\mathrm{C}$ and polarization $\mathrm{HH}, \mathrm{HV}$, and VV. One Landsat-5 TM images were also used in this research. SAR and optical images were acquired 10 June 2003.

\section{Description of scattering models}

\subsection{The Integral equation model}

The IEM is a theoretical backscattering model applicable to a wide range of roughness values (Fung et al. 1992). The backscatter coefficient of the surface contribution is expressed as:

$\sigma_{p q}^{0}=\frac{k^{2}}{2} \exp \left(-2 \mathrm{k}_{z}^{2} \sigma^{2}\right) \sum_{n=1}^{\infty} \sigma^{2 n}\left|I_{p q}^{n}\right|^{2} \frac{W^{n}\left(-2 \mathrm{k}_{x}, 0\right)}{n !}$

With

$$
\begin{aligned}
& I_{p q}^{n}=\left(2 \mathrm{k}_{z}\right)^{n} f_{p q} \exp \left(-\mathrm{k}_{z}^{2} \sigma^{2}\right)+\frac{k_{z}^{n}\left[\mathrm{~F}_{p q}\left(-\mathrm{k}_{x}, 0\right)+\mathrm{F}_{p q}\left(\mathrm{k}_{x}, 0\right)\right]}{2} \\
& f_{V V}=\frac{2 R_{\|}}{\cos \theta} \\
& f_{H H}=\frac{2 R_{\perp}}{\cos \theta} \\
& W^{n}\left(\mathrm{k}_{x}, \mathrm{k}_{y}\right)=\frac{1}{2 \pi} \iint \rho^{n}(\mathrm{x}, \mathrm{y}) \exp \left(\mathrm{jk}_{x} \mathrm{x}+\mathrm{jk} \mathrm{k}_{y} \mathrm{y}\right) \mathrm{dxdy} \\
& F_{V V}\left(-\mathrm{k}_{x}, 0\right)+F_{V V}\left(\mathrm{k}_{x}, 0\right)=\frac{2 \sin ^{2} \theta\left(1+\mathrm{R}_{\|}\right)^{2}}{\cos \theta} . \\
& {\left[\left(1-\frac{1}{\varepsilon_{r}}\right)+\frac{\mu_{r} \varepsilon_{r}-\sin ^{2} \theta-\varepsilon_{r} \cos ^{2} \theta}{\varepsilon_{r}{ }^{2} \cos ^{2} \theta}\right]} \\
& F_{H H}\left(-\mathrm{k}_{x}, 0\right)+F_{H H}\left(\mathrm{k}_{x}, 0\right)=-\frac{2 \sin ^{2} \theta\left(1+\mathrm{R}_{\perp}\right)^{2}}{\cos \theta} . \\
& {\left[\left(1-\frac{1}{\mu_{r}}\right)+\frac{\mu_{r} \varepsilon_{r}-\sin ^{2} \theta-\mu_{r} \cos ^{2} \theta}{\mu_{r}^{2} \cos ^{2} \theta}\right]}
\end{aligned}
$$


Where $\mathrm{k}$ is the radar wave number, $k_{\mathrm{Z}}$ is equal to $k \cos \theta, \theta$ is the radar angle of incidence, $\sigma$ is the standard deviation of surface height, $\varepsilon_{r}$ is the relative permittivity (relative dielectric constant ) of the soil, $\mu_{r}$ is the relative permeability and $R_{\|}$ and $R_{\perp}$ are the vertically and horizontally polarized Fresnel reflection coefficient, respectively. pq is the co-polarization or cross-polarization ( $\mathrm{HH}, \mathrm{VV}$ and $\mathrm{HV}) . W^{n}\left(\mathrm{k}_{x}, \mathrm{k}_{y}\right)$ is the Fourier transform of the nth power of the surface correlation function. The surface correlation function $\rho(\mathrm{x}, \mathrm{y})$ with exponential distribution is given by $\rho(\mathrm{x}, \mathrm{y})=\exp \{-(|x|+|y|) / \mathrm{L}\}$ and surface correlation with Gaussian distribution is given by $\rho(x, y)$ $=\exp =\left\{-\left(\mathrm{x}^{2}+y^{2}\right) / \mathrm{L}^{2}\right\}$. Here, $\mathrm{L}$ is correlation length. In this study both of these correlation functions were examined and the results of exponential auto correlation function were much better than Gaussian auto correlation function. There for we use exponential auto correlation function in this study.

\subsection{The semi-empirical Dubois model}

Dubois et al. (1995) suggested a semi-empirical approach for modelling $\sigma_{H H}^{0}$ and $\sigma_{V V}^{0}$ radar backscatter coefficients, using scatterometer data. The expressions for $\sigma_{H H}^{0}$ and $\sigma_{V V}^{0}$ involve the angle of incidence $(\theta)$, the dielectric constant $\left(\varepsilon_{r}\right)$, the standard deviation of surface height $\left(h_{r m s}\right)$ and the wavelength $(\lambda=2 \pi / \mathrm{k}$, in $\mathrm{cm})$ :

$$
\begin{aligned}
& \sigma_{H H}^{0}=10^{-2.75}\left(\frac{\cos ^{1.5} \theta}{\sin ^{5} \theta}\right) 10^{0.028 \cdot \varepsilon_{r} \cdot \tan \theta}\left(\mathrm{k} \cdot \mathrm{h}_{r m s} \cdot \sin \theta\right)^{1.4} \lambda^{0.7} \\
& \sigma_{V V}^{0}=10^{-2.35}\left(\frac{\cos ^{3} \theta}{\sin ^{3} \theta}\right) 10^{0.046 \cdot \varepsilon_{r} \cdot \tan \theta}\left(\mathrm{k} \cdot \mathrm{h}_{r m s} \cdot \sin \theta\right)^{1.1} \lambda^{0.7}
\end{aligned}
$$

The algorithm is optimized for bare soils with $k . h_{r m s} \leq 2.5, m v \leq 35 \%$ and $\theta \geq 30^{\circ}$ (Dubois et al. 1995).

\subsection{The semi-empirical Oh model}

Oh (Oh et al. 1992, 1994, 2002, Oh 2004) developed a semiempirical backscattering model based on theoretical models, scatterometer measurements and airborne SAR observations over a wide variety of bare soil surfaces. The model relates the co-polarized ratio $\mathrm{p}=\sigma_{H H}^{0} / \sigma_{V V}^{0}$ and the cross-polarized ratio $\mathrm{q}$ $=\sigma_{H V}^{0} / \sigma_{V V}^{0}$ to incident angle $(\theta)$, wave number $(\mathrm{k})$, standard deviation of surface height $\left(h_{r m s}\right)$ and volumetric soil moisture (mv). The initial version of the $\mathrm{Oh}$ model was presented by $\mathrm{Oh}$ et al. (1992):

$$
\begin{aligned}
& p=\sigma_{H H}^{0} / \sigma_{V V}^{0}=\left[1-\left(\frac{\theta}{90^{\circ}}\right)^{1 / 3 \Gamma_{0}} \mathrm{e}^{-k \cdot h_{m m s}}\right]^{2} \\
& q=\sigma_{H V}^{0} / \sigma_{V V}^{0}=0.23 \sqrt{\Gamma_{0}}\left(1-\mathrm{e}^{-k \cdot h_{m m s}}\right)
\end{aligned}
$$

$$
\Gamma_{0}=\left|\frac{1-\sqrt{\varepsilon_{r}}}{1+\sqrt{\varepsilon_{r}}}\right|^{2}
$$

A new expression for q was proposed by Oh et al. (1994) to incorporate the effect of the incidence angle:

$$
q=\sigma_{H V}^{0} / \sigma_{V V}^{0}=0.25 \sqrt{\Gamma_{0}}\left(0.1+\sin ^{0.9} \theta\right)\left(1-\mathrm{e}^{-\left[1.4-1.6 \Gamma_{0}\right] k . h_{m s s}}\right)
$$

The expressions for $\mathrm{p}$ and $\mathrm{q}$ were again modified in 2002, and an expression was proposed for the cross-polarized backscatter coefficient (Oh et al. 2002):

$$
\begin{aligned}
& p=1-\left(\frac{\theta}{90^{\circ}}\right)^{0.35 . m v^{-0.65}} e^{-0.4\left(\left(\mathrm{k} . \mathrm{h}_{m s} s^{1)^{1.4}}\right.\right.} \\
& q=0.1\left(\frac{h_{r m s}}{L}+\sin 1.3 \theta\right)^{1.2}\left(1-\mathrm{e}^{-0.9\left(\mathrm{k} \cdot \mathrm{h}_{m s s}\right)^{0.8}}\right) \\
& \sigma_{H V}^{0}=0.11 m v^{0.7} \cos ^{2.2} \theta\left(1-\mathrm{e}^{-0.32\left(\mathrm{k} \cdot \mathrm{h}_{m s}\right)^{1.8}}\right)
\end{aligned}
$$

Given that the measurement of the correlation length is not exact (Oh and Kay 1998, Baghdadi et al. 2000) and that the ratio $\mathrm{q}$ is insensitive to the roughness parameter $(\mathrm{rms} / \mathrm{L}), \mathrm{Oh}$ (2004) proposed a new formulation for $\mathrm{q}$ that ignores the correlation length:

$$
\left.q=0.095(0.13+\sin 1.5 \theta)^{1.4}\left(1-\mathrm{e}^{-1.3\left(\mathrm{k}_{\mathrm{h}} \mathrm{h}_{m s}\right.}\right) 0.9\right)
$$

The algorithm is optimized for bare soils with $0.1 \leq k . h_{r m s} \leq 2.5$, $9 \% \leq m v \leq 31 \%$ and $10^{\circ} \leq \theta \leq 70^{\circ}$ (Oh et al. 1994).

\section{Comparison between modeled and measured data}

The performance of each scattering model is evaluated using the statistical indexes suggested by Willmott (1992):

Root mean square error

$R M S E=\sqrt{\frac{1}{N} \sum_{i=1}^{N}\left(\mathrm{P}_{i}-O_{i}\right)^{2}}$

Bias

$$
\text { Bias }=\frac{1}{N}\left(\mathrm{O}_{i}-\mathrm{P}_{i}\right)
$$

Here $\mathrm{P}$ is the model-predicted variable, $\mathrm{O}$ the observed variable and $\mathrm{N}$ the data number.

Figures $2 \mathrm{a}, \mathrm{b}$ and $\mathrm{c}$ present the IEM model results in $\mathrm{L}$ and $\mathrm{C}$ band for $\mathrm{HH}$ and $\mathrm{VV}$ polarization and figures $2 \mathrm{~d}$, e and $\mathrm{f}$ present the Dubois model results in $\mathrm{L}$ and $\mathrm{C}$ band for back scatter coefficients $\sigma_{H H}^{0}$ and $\sigma_{V V}^{0}$, and finally figures $2 \mathrm{~g}, \mathrm{~h}, \mathrm{i}$ and $\mathrm{j}$ present the $\mathrm{Oh}$ model results in $\mathrm{L}$ and $\mathrm{C}$ band for back scatter coefficients $\mathrm{p}=\sigma_{H H}^{0} / \sigma_{V V}^{0}, \mathrm{q}=\sigma_{H V}^{0} / \sigma_{V V}^{0}$ and $\sigma_{H V}^{0}$ from 1992, 1994, 2002 and 2004 version.

Where 
(a)
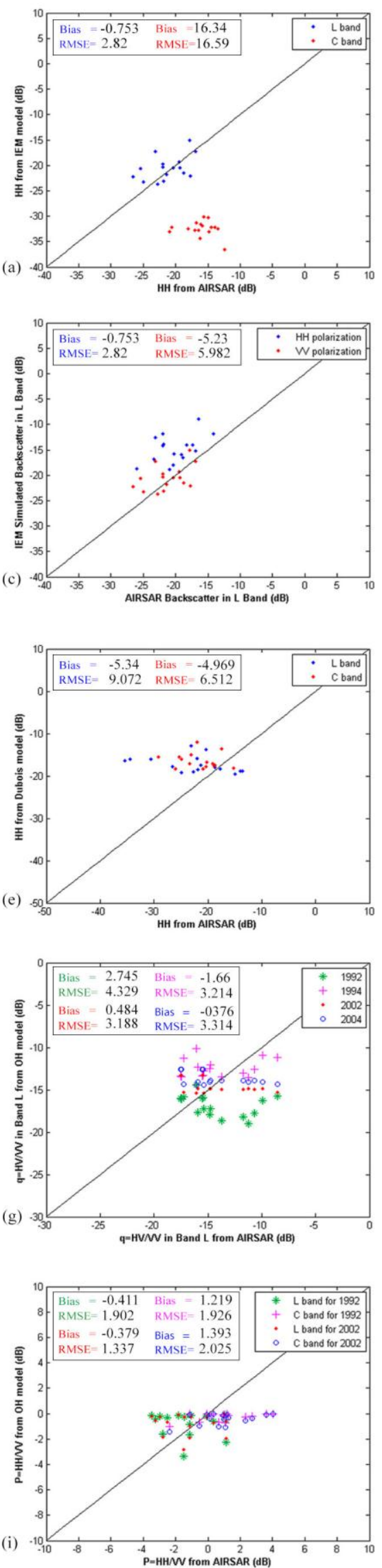
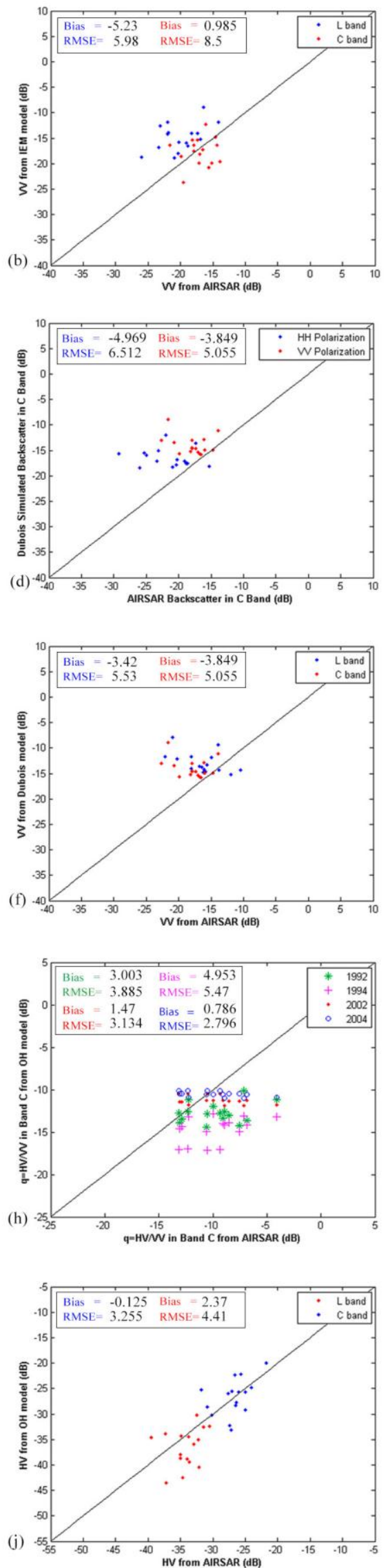

Figure 2. $\mathrm{a}, \mathrm{b}$ and $\mathrm{c}$ present the IEM model results in $\mathrm{L}$ and $\mathrm{C}$ band for $\mathrm{HH}$ and VV polarization and $\mathrm{d}$, e and $\mathrm{f}$ present the Dubois model results in $\mathrm{L}$ and $\mathrm{C}$ band for back scatter coefficients $\sigma_{H H}^{0}$ and $\sigma_{V V}^{0}$, and finally g, i and j present the Oh model results in $\mathrm{L}$ and $\mathrm{C}$ band for back scatter coefficients p, q and $\sigma_{H V}^{0}$ from 1992, 1994, 2002 and 2004 version. 


\section{Discussion}

\subsection{Evaluation of the IEM model}

In this study the backscatter coefficients of IEM model were simulated in $\mathrm{L}$ and $\mathrm{C}$ band and $\mathrm{HH}$ and $\mathrm{VV}$ polarization over three different vegetation canopy covers and three different soil depths. The results obtained show that IEM model is frequently tended to under-estimate the radar signal in $\mathrm{C}$ band (Figure $2 \mathrm{a}$, b) and over-estimate it in L band (Figure 2a, b). Figure 2b shows that errors obtained in $\mathrm{L}$ band are much smaller than those obtained in $\mathrm{C}$ band (RMSE $=5.982 \mathrm{~dB}$ for $\mathrm{L}$ band and $8.501 \mathrm{~dB}$ for $\mathrm{C}$ band) and also figure $2 \mathrm{c}$ shows that in $\mathrm{L}$ band the $\mathrm{HH}$ backscatter results were more precise than $\mathrm{VV}$ backscatter (RMSE $=2.82 \mathrm{~dB}$ for $\mathrm{HH}$ and $5.982 \mathrm{~dB}$ for $\mathrm{VV}$ ). Examination of this model in three different soil depth $(0-3 \mathrm{~cm}$ ,3-6 $\mathrm{cm}$ and $0-6 \mathrm{~cm}$ ) shows that the best results are related to 0 $3 \mathrm{~cm}$ soil depth followed by $0-6 \mathrm{~cm}$ soil depth. The $3-6 \mathrm{~cm}$ soil depth results shows the weakest correlation. As an example for $\mathrm{L}$ band and VV polarization in different soil depths the RMSE values are equal to $5.982 \mathrm{~dB}$ for $0-3 \mathrm{~cm}, 7.007 \mathrm{~dB}$ for $0-6 \mathrm{~cm}$ and $7.859 \mathrm{~dB}$ for $3-6 \mathrm{~cm}$. The results of $\mathrm{C}$ band in different soil depth shows that this band cannot simulate backscatter in depth more than $0-3 \mathrm{~cm}$ due to its small wavelength and in depths such as $0-6 \mathrm{~cm}$ or 3-6 $\mathrm{cm}$ errors are too large. (RMSE $=8.501$ $\mathrm{dB}$ in $0-3 \mathrm{~cm}, 53.803 \mathrm{~dB}$ in $3-6 \mathrm{~cm}$ and $48.953 \mathrm{~dB}$ in $06 \mathrm{~cm}$ ). This model also examined in different vegetation canopy covers and for this purpose Normal Differences Vegetation Index (NDVI) was used. All backscatters in $\mathrm{L}$ and $\mathrm{C}$ band were simulated in three different NDVI (NDVI $\leq 0.2,0.2<$ NDVI $\leq$ 0.4 and $0.4<$ NDVI $\leq 0.6$ ). The results obtained show that in both bands and all backscatters the best results are related to bare soil area with NDVI $\leq 0.2$ and after that for $0.2<\mathrm{NDVI} \leq$ 0.4 and finally $0.4<\mathrm{NDVI} \leq 0.6$. For example in $\mathrm{L}$ band and $\mathrm{HH}$ polarization the rms error is about $5.982 \mathrm{~dB}$ for NDVI $\leq$ $0.2,6.253 \mathrm{~dB}$ for $0.2<\mathrm{NDVI} \leq 0.4$ and $8.185 \mathrm{~dB}$ for $0.4<$ $\mathrm{NDVI} \leq 0.6$. These results have been expected since in the IEM model there is no parameter to model the impact of vegetation cover. Therefore in order to estimate soil moisture with this model in area with vegetation cover propose that impact of vegetation cover omit from the radar backscatter before suing this model.

\subsection{Evaluation of the Dubois model}

In this study the backscatter coefficients of Dubois model namely $\sigma_{H H}^{0}$ and $\sigma_{V V}^{0}$ were simulated in $\mathrm{L}$ and $\mathrm{C}$ band over two different vegetation canopy covers and three different soil depths. Generally speaking, the Dubois model tends to overestimate the radar signal in all bands and backscatters (figure 2(d), (e) and (f)). Results obtained show that in C band the Dubois model agrees closely to the measured data than $\mathrm{L}$ band and also the errors obtained in VV polarization are smaller than those observed in $\mathrm{HH}$ polarization in both bands (Figure 2(e) and (f)). Thus the best results obtained in $\mathrm{C}$ band and VV polarization $(\mathrm{RMSE}=5.055 \mathrm{~dB})$. Examination of this model in three different soil depth $(0-3 \mathrm{~cm}, 3-6 \mathrm{~cm}$ and $0-6 \mathrm{~cm})$ shows the same behaviour as IEM model that the best results are related to $0-3 \mathrm{~cm}$ and then $0-6 \mathrm{~cm}$ and finally $3-6 \mathrm{~cm}$. (RMSE for $\mathrm{C}$ band and $\mathrm{VV}$ polarization in $0-3 \mathrm{~cm}=5.055 \mathrm{~dB}, 0-6 \mathrm{~cm}=$ $5.826 \mathrm{~dB}$ and $3-6 \mathrm{~cm}=6.563 \mathrm{~dB}$ ). This model was suggested by Dubois et al. (1995) for bare surface however they suggested that the inversion of their algorithm could be applied to surfaces with NDVI as high as 0.4.(Dubois et al. (1995)).
Therefor in this research the Dubois model was examined under two vegetation canopy cover. The results obtained show that the both $\mathrm{HH}$ and $\mathrm{VV}$ backscatters in $\mathrm{C}$ band and the $\mathrm{VV}$ backscatter in $\mathrm{L}$ band were simulated more precisely in bare soil area with NDVI $\leq 0.2$ that in area with moderate vegetation cover $0.2<\mathrm{NDVI} \leq 0.4$. However the $\mathrm{HH}$ backscatter in $\mathrm{L}$ band was simulated more precisely in area with $0.2<$ NDVI $\leq 0.4$ than in bare soil area with NDVI $\leq 0.2$.

\subsection{Evaluation of the $\mathrm{OH}$ model}

In this study the all backscatter coefficients of $\mathrm{OH}$ model which had been developed since 1992 to 2002 were simulated in L and $\mathrm{C}$ band over three different soil depths. The Oh model tends to over-estimate the radar signal in $\mathrm{C}$ bands except for backscatter coefficient $\sigma_{H V}^{0}$ (Figure 2(h) and (i)) but in $\mathrm{L}$ band $\mathrm{OH}$ model mostly tends to under-estimate the radar signal except for ratio q from the 1994 and 2002 version (Figure 2(g) and (i)). Figure 2(i) shows that ratio $\mathrm{p}$ from the 1992 and 2002 version can simulate radar signal in $\mathrm{L}$ band better than in $\mathrm{C}$ band $(\mathrm{RMSE}=$ $1.337059418 \mathrm{~dB}$ for ratio $\mathrm{p}$ in $\mathrm{L}$ band and $2.025981843 \mathrm{~dB}$ in $\mathrm{C}$ band), and the best result of ratio $p$ obtained in $\mathrm{L}$ band and from the 2002 version. However in $\mathrm{C}$ band ratio $\mathrm{p}$ is slightly better in the 1992 version than the 2002 version (Figure 2(i)). Other results for ratio $\mathrm{q}$ illustrate that this ratio can estimate radar backscatter mostly better in $\mathrm{C}$ band rather than L band (Figure $2(\mathrm{~g}),(\mathrm{h}))$. For example all cross-polarized ratio $\mathrm{q}$ results for 1992, 2002 and 2004 version in C band were more precise than those in $\mathrm{L}$ band. The results obtained from the backscatter coefficient $\sigma_{H V}^{0}$ show that this coefficient was over-estimated by the Oh model in L band and under-estimated by this model in $\mathrm{C}$ band (Figure 2(j)). More over the errors obtained for this coefficient in $\mathrm{C}$ band are smaller than those obtained in $\mathrm{L}$ band (RMSE = 3.255276629 dB in C band and $4.417182609 \mathrm{~dB}$ in $\mathrm{L}$ band). Examination of this model in three different soil depths $(0-3 \mathrm{~cm}, 3-6 \mathrm{~cm}$ and $0-6 \mathrm{~cm})$ shows that the best results mostly are related to $0-3 \mathrm{~cm}$ soil depth and after that to $0-6 \mathrm{~cm}$ soil depth and finally to the $3-6 \mathrm{~cm}$ soil depth However, the ratio $\mathrm{q}$ from the 1994 ratio in just $\mathrm{C}$ band show completely different behaviour. For this ratios the best result are related to $3-6 \mathrm{~cm}$ soil depth, after that to the $0-6 \mathrm{~cm}$ soil depth and finally to the $0-3 \mathrm{~cm}$ soil depth. However our data base is not big enough to for a detailed study of the behaviour of this error.

\section{Conclusion}

The objective of this article is to evaluate the semi-empirical models of $\mathrm{Oh}$ and Dubois and the theoretical integral equation model (IEM) using L and C-bands with ground measurements over vegetation cover and bare soli in agricultural environments and different soil depths. The results show that Dubois model tend to over-estimate the radar response in both bands but IEM model and Oh model frequently over-estimate the radar response in $\mathrm{L}$ band and under-estimate them in $\mathrm{C}$ band. As mentioned earlier, by examination of models in different soil depths and vegetation canopy covers, best results obtained in 0 $3 \mathrm{~cm}$ depths and area with NDVI $\leq 0.2$.

\section{References:}

Alvarez-Mozos, J., Casali, J., Gonzalez-Audicana, M., and Verhoest, N.E.C. 2005. Correlation between ground measured 
soil moisture and RADARSAT-1 derived backscattering coefficient over an agricultural catchment of Navarre (North of Spain). Biosystems Engineering, Vol. 92, No. 1, pp. 119133. doi: 10.1016/j.biosystemseng.2005.06.008.

Atemma, E.P., and Ulaby, F.T. 1978. Vegetation modeled as water cloud.Radio Science, Vol. 13, No. 2, pp. 357 364. doi: 10.1029/RS013i002 p00357.

Baghdadi, N., Gherboudj, I., Zribi, M., Sahebi, M., Bonn, F. and King, C., 2004, Semi-empirical calibration of the IEM backscattering model using radar images and moisture and roughness field measurements. International Journal of Remote Sensing, 25, pp. 3593-3623.

Baghdadi, N., and Zribi, M. (2006) 'Evaluation of radar backscatter models IEM, OH and Dubois using experimental observations', International Journal of Remote Sensing, 27: 18, $3831-3852$

Beljaars, A., Viterbo, P., Miller, M., and Betts, A. 1996. The anomalous rainfall over the United States during July 1993: sensitivity to land surface parameterization and soil moisture anomalies. Monthly Weather Reviews, Vol. 124, No. 3, pp. 362383 .

Bindlish, R. and Barros, A.P., 2000, Multifrequency soil moisture inversion from SAR measurements with the use of IEM. Remote Sensing of Environment, 71, pp. 67-88.

Dubois, P.C., van Zyl, J., and Engman, T. 1995. Measuring soil moisture with imaging radar. IEEE Transactions on Geoscience and Remote Sensing, Vol. 33, No. 6, pp. 915 926. doi: 10.1109/TGRS.1995.477194.

Fung, A.K., Li, Z., and Chen, K.S. 1992. Backscattering from a randomly rough dielectric surface. IEEE Transactions on Geoscience and Remote Sensing, Vol. 30, No. 2, 356 369. doi: 10.1109/36.134085.

Georgakakos, K.P., Guetter, A.K., and Sperfslage J.A. 1996. Estimation of flash flood potential for large areas. In Destructive Water: Water-Caused Natural Disasters, their Abatement and Control. Edited by G.H. Leavesley, H.F. Lins, F. Nobilis, R.S. Parker, V.R. Schneider and F.H.M. van de Ven. IAHS, California. pp. 8793.

Hallikainen, M., Ulaby, F., Dobson, F., Elrayes, M. and WU, L., 1985, Microwave dielectric behaviour of wet soil. Part I: empirical models and experimental observations. IEEE Transactions on Geoscience and Remote Sensing, 23, pp. 2534.

Oh, Y., 2004, Quantitative retrieval of soil moisture content and surface roughness from multipolarized radar observations of bare soil surfaces. IEEE Transactions on Geoscience and Remote Sensing, 42, pp. 596-601.

Oh, Y., Sarabandi, K. and Ulaby, F.T., 1992, An empirical model and an inversion technique for radar scattering from bare soil surfaces. IEEE Transactions on Geoscience and Remote Sensing, 30, pp. 370-382.

Oh, Y., Sarabandi, K. and Ulaby, F.T., 1994, An inversion algorithm for retrieving soi moisture and surface roughness from polarimetric radar observation. Proceedings IGARSS'94, Pasadena, USA. IEEE catalog no. 94CH3378-7, III, pp. 15821584, (New York: IEEE).

Oh, Y., Sarabandi, K. and Ulaby, F.T., 2002, Semi-empirical model of the ensemble-averaged differential Mueller matrix for microwave backscattering from bare soil surfaces. IEEE Transactions on Geoscience and Remote Sensing, 40, pp. 13481355.

Panciera, R., Walker, J.P., and Merlin, O. 2009. Improved understanding of soil surface roughness parameterization for Lband passive microwave soil moisture retrieval. IEEE Transactions on Geoscience and Remote Sensing, Vol. 6, No. 4, pp. 625 629. doi: 10.1109/LGRS.2009.2013369.

Rakotoarivony, L., Taconet, O., Vidal-madjar, D., Bellemain, P. and Benalle'gue, M., 1996, Radar backscattering over agricultural bare soils. Journal of Electromagnetic Waves and Applications, 10, pp. 187-209.

Satalino, G., Mattia, F., Davidson, M.,Letoan, T., Pasquariello, G.and Borgeaud, M., 2002, On current limits of soil moisture retrieval from ERS-SAR data. IEEE Transactions on Geoscience and Remote Sensing, GE-24, pp. 2438-2447.

Shi, J., Wang, J., Hsu, A.Y., O'neill, P.E. and Engman, E.T., 1997, Estimation of bare surface soil moisture and surface roughness parameter using L-band SAR images data. IEEE Transactions on Geoscience and Remote Sensing, 33, pp. 915926.

Srivastava, H.S., Patel, P., Sharma, Y., and Navalgund, R.R. 2009. Large-area soil moisture estimation using multiincidence-angle RADARSAT-1 SAR data. IEEE Transactions on Geoscience Remote Sensing, Vol. 47, No. 8, pp. 2528 2535. doi: 10.1109/TGRS.2009.2018448.

Ulaby, F.T., Dubois, P.C., and van Zyl, J. 1996. Radar mapping of surface soil moisture. Journal of Hydrology, Vol. 184, Nos. 1 2, pp. 57 84. doi: 10.1016/0022-1694(95)02968

Willmott, C.J., 1992, Some comments on the evaluation of model performance. Bulletin American Meteorological Society, 11, pp. 1309-1313.

Zribi, M., Andre ', C., and Decharme, B. 2008. A method for soil moisture estimation in western Africa based on the ERS scatterometer. IEEE Transactions on Geoscience and Remote Sensing, Vol. 46, No. 2, pp. 438448. doi: 10.1109/TGRS.2007.904582.

Zribi, M., Taconet, O., Lehegarat-mascle, S., Vidal-madjar, D., Emblanch, C., Loumangne, C. and Normand, M., 1997, Backscattering behavior and simulation: Comparison over bare soils using SIR-C/X-SAR and ERASME 1994 data over Orgeval. Remote Sensing of Environment, 59, pp. 308-320. 